\title{
Simplicity, safety, and acceptability of insulin pen use versus the conventional vial/syringe device in patients with type I and type 2 diabetes mellitus in Lebanon
}

\author{
This article was published in the following Dove Press journal: \\ Patient Preference and Adherence \\ 27 March 2015 \\ Number of times this article has been viewed
}

\section{Wijdan H Ramadan' \\ Noura A Khreis ${ }^{2}$ \\ Wissam K Kabbara' \\ 'Department of Pharmacy Practice, School of Pharmacy, Lebanese American University, Byblos, Lebanon; ${ }^{2}$ King Faisal Specialist Hospital and Research Center, Riyadh, Saudi Arabia}

Correspondence: Wijdan H Ramadan Department of Pharmacy Practice School of Pharmacy Lebanese American University PO Box 36 - F 53, Byblos, Lebanon Tel $+96 \mid 9547249$ Ext 2267 Fax+96I 9547256 Ext 2897 Email wramadan@lau.edu.lb
Background: The aim of the study was to evaluate the simplicity, safety, patients' preference, and convenience of the administration of insulin using the pen device versus the conventional vial/syringe in patients with diabetes.

Methods: This observational study was conducted in multiple community pharmacies in Lebanon. The investigators interviewed patients with diabetes using an insulin pen or conventional vial/ syringe. A total of 74 questionnaires were filled over a period of 6 months. Answers were entered into the Statistical Package for Social Sciences (SPSS) software and Excel spreadsheet. $t$-test, logistic regression analysis, and correlation analysis were used in order to analyze the results.

Results: A higher percentage of patients from the insulin pen users group (95.2\%) found the method easy to use as compared to only $46.7 \%$ of the insulin conventional users group $(P 0.001$, relative risk [RR]: $2.041,95 \%$ confidence interval [CI]: $1.178-3.535)$. Moreover, $61.9 \%$ and $26.7 \%$ of pen users and conventional users, respectively, could read the scale easily $(P 0.037$, RR $2.321,95 \%$ CI: $0.940-5.731$ ), while $85.7 \%$ of pen users found it more convenient shifting to pen and $86.7 \%$ of the conventional users would want to shift to pen if it had the same cost. Pain perception was statistically different between the groups. A much higher percentage $(76.2 \%)$ of pen users showed no pain during injection compared to only $26.7 \%$ of conventional users (P 0.003, RR 2.857, 95\% CI: 1.194-6.838).

Conclusion: The insulin pen was significantly much easier to use and less painful than the conventional vial/syringe. Proper education on the methods of administration/storage and disposal of needles/syringes is needed in both groups.

Keywords: diabetes, insulin pen, conventional vial/syringe, hypoglycemia, secretagogue, pain perception, needle phobia

\section{Introduction}

Diabetes mellitus is an epidemic critical disease requiring continuous medical care. The World Health Organization (WHO) estimated that diabetes mellitus is projected to become the seventh leading cause of death within the coming 15 years. ${ }^{1}$ Due to population growth alone, the number of patients suffering from diabetes worldwide is expected to double from 171 million in 2000 to more than 366 million in 2030. The estimated cost of treatment is also expected to increase to US\$192 billion in $2020 .^{2}$ Type 1 diabetes mellitus results from the total destruction of the pancreatic beta cells leading to total insulin deficiency, thus rendering the body wholly dependent on exogenous insulin for therapy. Type 2 diabetes mellitus often requires multiple oral antidiabetic 
or hypoglycemic agents and/or insulin as an option in step 2 therapy. ${ }^{3}$ The American Heart Association (ADA) consensus algorithm lists insulin as an option after life style modification and metformin or when $\mathrm{HbA}_{1 \mathrm{c}}>8.5 \%{ }^{4}$

Studies have shown that insulin therapy can improve insulin sensitivity and glycemic control as well as decrease the incidence of micro- and macrovascular complications such as neuropathy, retinopathy, nephropathy, and cardiovascular diseases. ${ }^{4}$ The ADA recommends for all patients with diabetes, who are not at high risk for hypoglycemia, a tight glycemic control, which is defined as the target level of $\mathrm{HbA}_{1 \mathrm{c}}<7 \%$. This association stated that a total cost savings of $\$ 50$ billion could be achieved over 10 years in all patients with diabetes if this target level is attained. ${ }^{5}$ Diabetes teams need to work along with their patients to ensure that insulin therapy is initiated early enough, when needed, to maintain tight glycemic control and minimize diabetes-related diseases and costs. Despite this known benefit of insulin therapy, physicians and patients are still reluctant to start this therapy for multiple reasons. In fact, the UKPDS (United Kingdom Prospective Diabetes Study) showed that $27 \%$ of patients with type 2 diabetes mellitus refused initiating insulin when asked by their doctors, and, in the DAWN (Diabetes Attitudes, Wishes and Needs) study, 50\%-55\% of physicians delayed insulin therapy for their patients because of the fear of noncompliance and poor patient adherence. ${ }^{6,7}$

The National Health and Nutrition Examination Survey (NHANES) proved that the use of insulin dropped drastically from $24 \%$ to $16 \%$ between 1990 and $2000 .^{8}$ This reduction can be explained by several factors, one of which is associated with the complexity of the administration of insulin using the vial/ syringe device at that time. ${ }^{9}$ Other reasons may be the distress associated with the fear of self-injection, social stigma, and troublesome dosing - especially when patients have to mix different types of insulin, as well as the fear of hypoglycemia. ${ }^{2}$ All these factors make patients hesitant to initiate this "complex therapy" ${ }^{8}$ With the development of insulin pens, the patients' perceptions of insulin therapy improved and patients were able to overcome some of the barriers stated earlier. ${ }^{9}$

Insulin pens were first introduced in 1985 by Novo Nordisk $\left(\right.$ NovoPen $^{\circledR}$ ), but the latter still needed the loading step, which was totally eliminated in 1989 by the development of the first fully disposable prefilled insulin pen $\left(\right.$ NovoLet $\left.^{\circledR}\right) .{ }^{10,11}$ The aim behind such a development was to improve treatment compliance. Pens are simple to use, and patient preference and satisfaction with insulin pens may lead to better adherence and thus better glycemic control which, in return, leads to reduced health costs. ${ }^{12}$
Pawaskar et al compared the costs related to starting an insulin pen versus the conventional vial/syringe in patients with type 2 diabetes mellitus. One thousand three hundred and thirty-two patients were analyzed and the total annual health care costs averaged $\$ 14,900$ in the pen group versus $\$ 32,000$ in the syringe group. Interestingly enough is the fact that the cost of hospitalization of the pen group was more reduced. ${ }^{13}$ This finding was emphasized by Asamoah in his article titled "Insulin pen-the 'iPod' for insulin delivery (why pen wins over syringe)". ${ }^{14}$ An explanation of such cost saving is the possibility of less insulin wastage due to expiration with the insulin pen since one vial contains 1,000 units of insulin as compared of one box of 5 pens containing 1,500 units of insulin in total. ${ }^{3}$ Another study, by Lee et al analyzed patients' adherence and hypoglycemic incidents in patients who converted to pen use. It showed that converting to pen significantly improved medication adherence and reduced hypoglycemic episodes (odds ratio [OR]: $0.50, P<0.05$ ). ${ }^{15}$

Moreover, the simplicity of pen use is particularly important not only to older patients suffering from impaired manual dexterity and tremors, but also for younger individuals who are too busy to devote much time to their injections. ${ }^{16,17}$ Insulin pens are portable, thus they offer greater flexibility in day-to-day living especially in younger patients. Lee et al in another study looked at the quality-of-life improvement when shifting to insulin pens in 65 patients. Patients received an assessment of glucose control after 12 weeks and were asked to fill out a questionnaire on health-related quality of life. The study showed that the physical component of the Short-Form Health Survey (SF-36) was significantly higher in the pen group with a $P$-value of $0.037 .{ }^{18} \mathrm{It}$, thus, revealed that using insulin pens improved glycemic control and health-related quality of life in patients with diabetes, hence improving functional status, which is an important aspect of this millennium.

The objective of this study was to assess the simplicity, safety, patients' preference, and convenience of the administration of insulin using the pen versus the conventional vial/syringe device. Other endpoints target the awareness of the method of administration of insulin via the pen device and the conventional vial/syringe. In addition, some endpoints will be stratified by possible confounders.

\section{Methods}

\section{Setting and design}

A concurrent, prospective observational study was conducted at five community pharmacies in Lebanon, in the Beirut area, over a period of 6 months. Patients with diabetes using 
insulin and visiting pharmacies to purchase insulin products were asked if they were willing to participate in the study. Patients whose family members came to the pharmacies to buy the insulin were asked about the telephone number of the patients and about the possibility of calling them. Phone interviews were done when patients consented to participate in the study. The investigators had prepared a structured questionnaire that was used in order to conduct the survey (Figures S1 and S2). The study was approved by the Lebanese American University Institutional Review Board and a waiver of consent was obtained to fill out the questionnaire.

\section{Inclusion/exclusion criteria}

Patients with type 1 and type 2 diabetes mellitus, aged 10 years or older from both genders, and using insulin by self-injection or receiving help from family members for insulin administration were included. Female patients taking insulin for gestational diabetes, hospitalized patients, patients on insulin pumps, patients having severe systemic diseases such as active cancer, and patients with psychiatric disorders were excluded. Patients receiving insulin injections from health care professionals were excluded as well.

\section{Sources of data}

The primary, secondary, and tertiary investigators interviewed patients entering community pharmacies from 9 am until $4 \mathrm{pm}$. The study consisted of a well-structured questionnaire used for data collection that is divided into two segments. The first segment targeted conventional insulin users, whereas the second targeted insulin pen users. Each segment is divided into three sections. The first two sections were common to both segments. The first section consisted of 13 general questions about the patient's demographics as well as diabetes type, duration of insulin use, physician visit frequency, fasting blood glucose and $\mathrm{HbA}_{1 \mathrm{c}}$ monitoring, concomitant oral hypoglycemic use, and other comorbidities. The second section included 12 questions highlighting the administration techniques. The last section targeted either insulin pen users or conventional vial/syringe users. At the end of data collection, 74 surveys had been filled out. The questions were converted to endpoints in order to meet the objective of the study. The primary endpoints were the simplicity and safety of administration, as well as patients' preference and convenience. Simplicity of administration was analyzed according to answers in the survey about the following: how easy it is to use the device (pen versus conventional) and to read the scale, and how comfortable the responder would feel using a pen without a guide. Safety of administration was targeted by questions related to pain perception, hypoglycemic episodes, and bruises at the site of administration. Information about patients' preference and convenience were collected through patients' responses to two different questions: patients on insulin pens were asked if it was more convenient when shifting to pen, and those using a conventional vial/syringe were asked if they would prefer shifting to a pen if it were the same cost as a conventional $\mathrm{vial} /$ syringe. A secondary endpoint was the awareness of the method of administration in terms of A: proper storage (in the fridge before opening and at room temperature or fridge after opening); B: method of shaking (rubbing as a proper method); C: angle of administration (answered as $45^{\circ}$ or $90^{\circ}$ as a correct method according to the level of obesity [body mass index]); D: rotating the site of injection (rotating within the same region for morning dose and another region for evening dose or rotating between sites from one injection to another); E: cleaning the site of administration; F: examining the suspension before use; G: using a new needle for every injection; H: throwing away needles directly after injection; and I: releasing trapped air from the vial/syringe (for conventional device) or hearing the click (for pen).

"Administration procedures" included questions about the awareness of each method (items A-I) mentioned in the previous paragraph. The responses were converted to either "incorrect" (0) or "correct" (1). "Safety and simplicity" included information about pain perception, bruises, hypoglycemia, ease of use, and reading the scale. Again, answers were converted to either " 0 " as more negative impact or " 1 " as less negative impact on patients. Correlation was conducted to analyze the relationship between ease of use and insulin duration. Three categories were developed for ease of use: 1) easy; 2) intermediate; and 3) hard, and two categories were used for insulin duration: 1) 1-5 years and 2) $>5$ years. As for the relation between reading the scale and age, a correlation was also performed. The patients were divided into two groups: 0 ) all ages ( $\leq 60$ years); and 1 ) ages $>60$ years. Three categories were developed for reading the scale: 1) easy; 2) intermediate; and 3) hard. Bruises at the site of administration were also stratified by the type of other comorbidities and the likelihood of taking concomitant anticoagulant or antiplatelet drugs that increase the risk of bleeding. A correlation was conducted to analyze the relationship between patients having bruises with patients having stroke/ischemic heart disease, and with patients who do not correctly rotate between the sites of injection. Hypoglycemic episodes were classified as less frequent (less than one 
episode in 6 months) or more frequent (more than one episode in 6 months). Hypoglycemia episodes were identified if the patient experienced symptoms of hypoglycemia that may or may not be confirmed by glucose level check and were stratified by the age and whether or not the patient took other oral hypoglycemic agents. A correlation was conducted to relate the frequency of hypoglycemia ([0] less frequent; [1] more frequent) to two possible confounders such as secretagogue use ([0] not using secretagogues; [1] using secretagogues) and age group, mainly elderly ([0] all ages $\leq 60$ years; [1] ages $>60$ years).

\section{Statistical analysis}

Data were processed and analyzed through the application of two software programs: the Statistical Package for the Social Sciences (SPSS version 19; IBM Corporation, Armonk, NY, USA) and Microsoft Excel. Responses were tabulated and cross-tabulated. Percentages, $P$-values, RR, and 95\% confidence interval (CI) were calculated. Data were converted to dichotomous, binary-type variables. Thus, $t$-test, logistic regression, and binary correlation were applied in order to analyze the results.

\section{Results}

In this study, a total of 74 patients were surveyed, of whom 43 were using an insulin pen and 31 were using a conventional vial/syringe. Demographic information is shown in Table 1.

Most of the patients using the insulin pen $(81 \%)$ had been taught about the administration techniques by health care professionals (physicians or pharmacists). Of patients using insulin for more than 5 years, $52.38 \%$ of pen users found their device easy to use versus $33.33 \%$ of the conventional vial/ syringe users. For pen users (Table 2), there was a significant negative correlation between ease of use and the duration of insulin use at 5\% level of significance.

When asked about how comfortable they would feel using a pen without a guide, $62 \%$ of insulin pen users answered "quite comfortable" and "very comfortable". As for reading the scale, $61.9 \%$ of pen users could read the scale easily versus $26.7 \%$ of conventional users ( $P 0.037$, RR $2.321,95 \%$ CI: $0.940-5.731)$. Because the elderly are prone to dexterity issues, this outcome (reading the scale) was stratified by age group, mainly for patients who were above 60 years of age having the most difficulty with reading the scale. Among pen users, $71.19 \%$ of the patients found reading the scale hard or intermediate, versus $76.45 \%$ of conventional users.
Table I Baseline demographic percentages of the 74 patients

\begin{tabular}{|c|c|c|}
\hline Demographics & Insulin pen & $\begin{array}{l}\text { Conventional } \\
\text { insulin device }\end{array}$ \\
\hline \multicolumn{3}{|l|}{ Sex } \\
\hline Female & $29.7 \%$ & $21.6 \%$ \\
\hline Male & $28.4 \%$ & $20.3 \%$ \\
\hline \multicolumn{3}{|l|}{ Age (years) } \\
\hline $10-20$ & $0.0 \%$ & $0.0 \%$ \\
\hline $21-30$ & $5.4 \%$ & $0.0 \%$ \\
\hline $31-40$ & $2.7 \%$ & $2.7 \%$ \\
\hline $41-60$ & $23.0 \%$ & $13.5 \%$ \\
\hline$>60$ & $27.0 \%$ & $25.7 \%$ \\
\hline \multicolumn{3}{|l|}{ BMI } \\
\hline Normal & $14.9 \%$ & $9.5 \%$ \\
\hline Overweight & $23.0 \%$ & $24.3 \%$ \\
\hline Obese & $20.3 \%$ & $8.1 \%$ \\
\hline \multicolumn{3}{|l|}{ Diabetes type } \\
\hline Type I & $4.1 \%$ & $2.7 \%$ \\
\hline Type 2 & $54.1 \%$ & $39.2 \%$ \\
\hline \multicolumn{3}{|c|}{ Diabetes duration (years) } \\
\hline $1-5$ & $6.8 \%$ & $5.4 \%$ \\
\hline $6-10$ & $12.2 \%$ & $0.0 \%$ \\
\hline $1 \mathrm{I}-20$ & $20.3 \%$ & $14.9 \%$ \\
\hline$>20$ & $18.9 \%$ & $21.6 \%$ \\
\hline \multicolumn{3}{|c|}{ Insulin use duration (years) } \\
\hline $1-5$ & $20.3 \%$ & $5.4 \%$ \\
\hline $6-10$ & $35.1 \%$ & $24.3 \%$ \\
\hline $1 \mathrm{I}-20$ & $2.7 \%$ & $9.5 \%$ \\
\hline$>20$ & $0.0 \%$ & $2.7 \%$ \\
\hline \multicolumn{3}{|c|}{ Insulin units per day } \\
\hline $10-20$ & $21.6 \%$ & $5.4 \%$ \\
\hline $21-30$ & $9.5 \%$ & $9.5 \%$ \\
\hline $31-40$ & $10.8 \%$ & $8.1 \%$ \\
\hline $4 I-50$ & $8.1 \%$ & $13.5 \%$ \\
\hline$>50$ & $8.1 \%$ & $5.4 \%$ \\
\hline \multicolumn{3}{|c|}{ Other oral hypoglycemic } \\
\hline Secretagogues & $12.2 \%$ & $16.2 \%$ \\
\hline Other antidiabetic & $45.9 \%$ & $25.7 \%$ \\
\hline \multicolumn{3}{|c|}{ Insulin injection frequency/day } \\
\hline Once & $21.6 \%$ & $10.8 \%$ \\
\hline Twice & $17.6 \%$ & $20.3 \%$ \\
\hline Other & $18.9 \%$ & $10.8 \%$ \\
\hline \multicolumn{3}{|c|}{$\mathrm{HbA}_{\mathrm{Ic}}$ monitoring frequency } \\
\hline Every 3 months & $10.8 \%$ & $10.8 \%$ \\
\hline Every 6 months & $32.4 \%$ & $16.2 \%$ \\
\hline$>6$ months & $12.2 \%$ & $14.9 \%$ \\
\hline NA & $2.7 \%$ & $0.0 \%$ \\
\hline \multicolumn{3}{|l|}{ Comorbidities } \\
\hline Others & $40.5 \%$ & $23.0 \%$ \\
\hline Stroke/IHD & $17.6 \%$ & $18.9 \%$ \\
\hline
\end{tabular}

Abbreviations: BMI, body mass index; IHD, ischemic heart disease; NA, not available.

There was a significant positive correlation between age and reading the scale at 5\% level for all patients and pen patients only (Table 2). Pain perception is a major barrier to accepting insulin therapy. A statistically significant higher 
Table 2 Correlations

\begin{tabular}{|c|c|c|c|}
\hline Type & All patients & Pen users & Conventional users \\
\hline \multicolumn{4}{|c|}{ Relationship between ease of use and duration of insulin use } \\
\hline Correlation & -0.18 & -0.53 & -0.02 \\
\hline$P$-value & 0.292 & 0.042 & 0.921 \\
\hline \multicolumn{4}{|c|}{ Relationship between age and reading the scale } \\
\hline Correlation & 0.37 & 0.44 & 0.20 \\
\hline$P$-value & 0.028 & 0.044 & 0.473 \\
\hline \multicolumn{4}{|c|}{ Relationship between hypoglycemia and secretagogues } \\
\hline Correlation & 0.08 & 0.17 & 0.39 \\
\hline$P$-value & 0.647 & 0.457 & 0.152 \\
\hline \multicolumn{4}{|c|}{ Relationship between hypoglycemia and age } \\
\hline Correlation & 0.36 & 0.34 & 0.39 \\
\hline$P$-value & 0.029 & 0.135 & 0.152 \\
\hline \multicolumn{4}{|c|}{ Relationship between bruises and stroke/IHD } \\
\hline Correlation & 0.17 & 0.13 & 0.18 \\
\hline$P$-value & 0.333 & 0.560 & 0.510 \\
\hline \multicolumn{4}{|c|}{ Relationship between bruises and site rotation } \\
\hline Correlation & 0.12 & 0.14 & 0.04 \\
\hline$P$-value & 0.477 & 0.552 & 0.887 \\
\hline
\end{tabular}

Abbreviation: IHD, ischemic heart disease.

percentage $(76.2 \%)$ of pen users reported no pain during injection compared to only $26.7 \%$ of the conventional users ( $P$ 0.003, RR 2.857, 95\% CI: 1.194-6.838).

No statistically significant difference was seen between the groups in the incidence of hypoglycemia ( $P$ 0.681, RR $1.33,95 \%$ CI: $0.666-1.854)$. In both insulin user groups, only $28.79 \%$ of those who reported more frequent episodes of hypoglycemia used secretagogues concurrently. The results in Table 2 show no significant correlation between hypoglycemia and secretagogue use. However, for all patients, there was a significant positive correlation between age and hypoglycemia at $5 \%$ level.

An additional safety outcome addressed in our study was the percentage of bruises at the site of administration. More patients among the conventional users developed bruises at the site of administration (73.3\%) as compared to $47.6 \%$ of the pen users. However, this difference was not statistically significant ( $P$ 0.123, RR 1.964, 95\% CI: 0.773-4.994). When stratified by concomitant stroke or arrhythmias as a disease state, it was found that $75.11 \%$ of the patients in both groups who developed bruises had concurrent stroke or arrhythmias, though there was no significant relationship between bruises and stroke/ischemic heart disease or rotation of injection sites from 74 tested samples for all patients, pen users, and conventional users (Table 2).

Moving to another primary endpoint, which studied patients' preference and convenience, $85.7 \%$ of pen users found it more convenient when shifting to pen, and $86.7 \%$ of conventional users would want to shift to the pen if it were the same cost as the conventional vial/syringe.

\section{Safety and simplicity impact analysis}

Safety and simplicity criteria were classified as a separate category including the following five safety-simplicity (SS) factors: pain perception; bruises; hypoglycemia; ease of use; and reading the scale.

\section{Correlation analysis}

A binary correlation between SS factors was conducted to analyze their impact on patients using the following scale: (0) more painful, more bruises, more hypoglycemia, hard to use, hard to read the scale and (1) less painful, less bruises, less hypoglycemia, easy to use, easy to read the scale, for both types of patients (conventional users; pen users). Pen use was significantly positively correlated to pain and ease of use at $1 \%$ level, reading the scale at $5 \%$ level, and bruises at $10 \%$ level (Table 3). However, there was no correlation with hypoglycemia episodes.

\section{Regression analysis}

A logistic regression analysis was conducted to analyze the impact of choosing the pen method over the conventional method due to SS factors. Results are shown in Table 3. Pain perception and ease of use were the two significant factors. The factor of bruises, however, needs a larger sample size to investigate, which has a margin of possibility of $12 \%$. Since 
Table 3 Safety-simplicity (SS) factors

\begin{tabular}{|c|c|c|c|c|c|c|}
\hline \multicolumn{7}{|c|}{ Binary correlation between pen and conventional methods and SS factors } \\
\hline SS factors & Pain perception & Bruises & Hypoglycemia & Ease of use & Reading the scale & \\
\hline Correlation & $54 \%$ & $30 \%$ & $0 \%$ & $55 \%$ & $35 \%$ & \\
\hline$P$-value & 0.001 & 0.073 & I & 0 & 0.038 & \\
\hline \multicolumn{7}{|c|}{ Logistic regression analysis for SS factors; G (-2 log likelihood): 21.5 I 0} \\
\hline SS factors & Pain perception & Bruises & Hypoglycemia & Ease of use & Reading the scale & Constant \\
\hline Coefficient & 3.98 & 2.14 & -2.20 & 5.32 & 0.97 & -5.67 \\
\hline Standard error & 1.58 & 1.39 & 1.73 & 2.23 & 1.42 & 2.27 \\
\hline$P$-value & 0.01 & 0.12 & 0.20 & 0.20 & 0.49 & 0.01 \\
\hline \multicolumn{7}{|c|}{ Logistic regression analysis for SS factors; G (-2 log likelihood): 23.553} \\
\hline SS factors & Pain perception & Bruises & Ease of use & Constant & & \\
\hline Coefficient & 3.33 & 1.53 & 4.32 & -5.40 & & \\
\hline Standard error & 1.26 & 1.10 & 1.62 & 1.94 & & \\
\hline$P$-value & 0.008 & 0.164 & 0.008 & 0.005 & & \\
\hline
\end{tabular}

Note: G: most used indicator in logistic regression to quantify the likelihood.

pain perception, ease of use and bruises are rather significant impact factors for treatment, a logistic regression analysis was conducted for the three mentioned factors (Table 3 ) and Equation (1) was developed:

$$
\begin{aligned}
\hat{g}(x)= & -5.40+3.33 \times \text { Pain Perception } \\
& +1.53 \times \text { bruises }+4.32 \times \text { Ease of Use }
\end{aligned}
$$

Equation (1) could be used to identify the type of patient according to the categories of answers to pain perception, bruises, and ease-of-use questions. For example, for patient ID \#1 with a pain perception answer equal to 1 (meaning the device is painful), bruises answer equal to 0 (meaning the patient is not developing bruises at the site of administration), and ease-of-use answer equal to 1 (meaning the device is easy to use), $\hat{g}(x)=-5.40+3.33 \times 1+1.53 \times 0+4.32 \times 1=2.25$, $y=\pi(x)=e^{\hat{g}(x)} / 1+e^{\hat{g}(x)}=e^{2.25} / 1+e^{2.25}=0.90$, which means there is a $90 \%$ chance that the patient will be a pen user, and the actual patient (ID \#1) is a pen user.

A secondary endpoint included patients' awareness of the method of administration of insulin. Only $50 \%$ of all insulin users (conventional and pen users) showed correct rotation of the injection site. Moreover, $63.9 \%$ of all insulin users were storing insulin correctly. As for the angle of administration, $44.4 \%$ of all insulin users showed a correct angle of administration. Similarly, $52.7 \%$ of all insulin users showed a correct method of shaking. When assessing the proper aseptic techniques of administration/disposal or cleaning the site of administration, unfortunately only $30.5 \%$ of all insulin users cleaned the site of injection before administration and only $27.7 \%$ used a new needle for every injection. Moreover, few patients (16.6\%) examined the suspension/solution before

\begin{tabular}{|c|c|c|c|c|c|c|c|c|c|}
\hline \multicolumn{10}{|c|}{ Percentage of correct administration procedures: comparison between insulin pen and conventional users } \\
\hline Administration procedures ${ }^{\mathrm{a}}$ & A & B & C & D & $\mathbf{E}$ & $\mathbf{F}$ & G & $\mathbf{H}$ & I \\
\hline Pen & $38 \%$ & $52 \%$ & $52 \%$ & $48 \%$ & $24 \%$ & $0 \%$ & $19 \%$ & $24 \%$ & $86 \%$ \\
\hline Conventional & $100 \%$ & $53 \%$ & $33 \%$ & $53 \%$ & $40 \%$ & $40 \%$ & $40 \%$ & $53 \%$ & $40 \%$ \\
\hline$P$-value & 0 & 0.96 & 0.27 & 0.74 & 0.31 & 0 & 0.18 & 0.07 & 0 \\
\hline \multicolumn{10}{|c|}{ Factor analysis of the administration procedures for insulin pen and conventional users } \\
\hline Administration procedures ${ }^{a}$ & A & B & C & D & $\mathbf{E}$ & $\mathbf{F}$ & G & $\mathbf{H}$ & I \\
\hline Correlation & -0.64 & -0.01 & 0.19 & -0.06 & -0.17 & -0.53 & -0.23 & -0.30 & 0.48 \\
\hline$P$-value & 0 & 0.957 & 0.27 & 0.744 & 0.31 & 0.0001 & 0.176 & 0.072 & 0.0003 \\
\hline \multicolumn{10}{|c|}{ Logistic regression analysis of administration procedures } \\
\hline Administration procedures ${ }^{\mathrm{a}}$ & A & B & C & D & $\mathbf{E}$ & $\mathbf{F}$ & G & $\mathbf{H}$ & Constant \\
\hline Coefficient & -38.42 & -0.53 & 19.04 & -0.53 & 0.53 & -38.48 & -15.03 & -22.46 & 38.95 \\
\hline Standard error & 12.33 & 1.53 & 8.45 & 1.53 & 1.53 & 15.33 & 47.31 & 45.84 & 12.33 \\
\hline$P$-value & I & 0.73 & 1 & 0.73 & 0.73 & $\mathrm{I}$ & 1 & $\mathrm{I}$ & I \\
\hline
\end{tabular}

Table 4 Administration procedures 
injections; $40 \%$ of the conventional users released trapped air before injections; and $36.1 \%$ of all insulin users threw needles away directly after injection.

\section{Administration procedures analysis t-test analysis}

The percentages of correctness for all administration procedures are calculated in Table 4, and a $t$-test was conducted to test the significance level of difference on administration procedures between pen and conventional users. Pen users, as compared to conventional users, had a significant lower percentage of correctness on storage ( $38 \%$ versus $100 \%$ ), on examining the suspension/solution ( $0 \%$ versus $40 \%$ ), and on throwing the needle away directly after injection (24\% versus 53\%).

\section{Correlation analysis}

A binary correlation was conducted between patient types ([0] conventional; [1] pen) and administration procedures ([0] incorrect; [1] correct). Results are shown in Table 4. Seven out of nine administration procedures were negatively correlated. Administration procedures A, F, and I were significantly correlated at $1 \%$ level, and procedure $\mathrm{H}$ was significantly correlated at $10 \%$ level.

\section{Regression analysis}

A logistic regression was conducted to test how the administration factors influence patients' preference of insulin pen over conventional vial/syringe device (Table 4). The results show that no administration procedure was a significant factor at 5\% level.

\section{Discussion}

Diabetes mellitus is a chronic disease that has a huge impact on patients' lives. Patients with diabetes need special attention and care in order to manage their lives. On top of frequent glucose monitoring, frequent physician visits, daily monitoring of carbohydrate intake, and lifestyle modifications, patients who are to be initiated on insulin therapy face several social and economic burdens that make this therapy more bothersome. From this perspective comes the attention on patients' preference for the type of insulin therapy. ${ }^{10}$ Our study targeted several outcomes to compare between insulin pen users and conventional vial/syringe users, and showed that patients have a higher preference for insulin pens in terms of ease of use. The results parallel those of Korytkowski et al in which $74 \%$ of patients indicated a preference for the pen over the vial/syringe (95\% CI: 71\%-87\%), compared with $20 \%$ who preferred the vial/syringe; $74 \%$ considered the pen easier to use overall, compared with $21 \%$ for the vial/syringe; and $85 \%$ of insulin pen users found reading the scale easy to use compared to only $10 \%$ of the conventional vials users who believe that reading the scale is easy to read. ${ }^{9}$ Insulin vials/syringes are disposable, light-weight, transparent (such that insulin can be inspected), and come with different needle sizes and syringes, thus are suitable for high doses up to 100 units. ${ }^{19}$ However, they are less socially acceptable, necessitate carrying a bottle and syringe, and require refrigeration for storage and adequate visual acuity when drawing a dose. Insulin pens, on the other hand, are more socially acceptable, portable, have a larger scale which simplifies dosages, and offer an audible "click" with each unit that overcomes many visual problems. ${ }^{20}$ In our study, $86 \%$ reported hearing the click with each insulin pen use. Insulin pens are perceived as less painful when compared to a conventional vial/syringe. In fact, needle phobia has been studied in many clinical trials. A study about the needle gauge and its association with pain was studied in 30 healthy volunteers; $40.3 \%$ reported that a needle of 27 gauge $/ 0.4 \mathrm{~mm}$ outer diameter was significantly more likely to cause pain compared with a needle of 30 gauge $/ 0.3 \mathrm{~mm}$ outer diameter. ${ }^{9}$ Another open-label, crossover study comparing patient preference and pain perception between the Micro Fine Plus ${ }^{\circledR}$ 31-gauge and the Microtapered NanoPass ${ }^{\circledR}$ 33-gauge needles showed that the 33-gauge lubricant-coated needle had a significantly superior $(P<0.001)$ overall patient satisfaction score with less fear and less bleeding tendency. ${ }^{20}$

In our study, the insulin pen was significantly less painful and easier to use, and the scale was easier to read, compared to the conventional vial/syringe. Needle phobia may be decreased by the shorter needles $(6-10 \mathrm{~mm})$ found in the pen device compared with the conventional syringe $(12 \mathrm{~mm})$. The drawback of insulin pen use is the fact that they are expensive.

The complexity of the administration of conventional insulin may expose the patients to serious safety implications. Previous studies showed that there is approximately 19\% error in the accuracy of the insulin dose drawn and the risk of error is higher with conventional syringes, especially when drawing doses below five insulin units. ${ }^{21,22}$ The results of our study showed that both groups $(29.63 \%$ and $41.26 \%$ of pen users and conventional users, respectively) were developing hypoglycemic episodes more frequently, which might be correlated to inaccuracy in insulin dosing. However, a major limitation of this study is that it did not quantify the number of hypoglycemic episodes nor the severity of hypoglycemia. 
Another major limitation is that the study is not a controlled one and the investigators did not have information about the exact dose of insulin taken nor knowledge about the lifestyle, food intake, or visual acuity status of the patients.

Other limitations include the small sample size, the limited number of community pharmacies included in the study, and the short duration of the study; added to this, the length of the questionnaire used made some patients reluctant to agree to be interviewed due to their limited free time. Moreover, most of the patients who entered the pharmacies had their insulin injected by the pharmacy staff, which led to their exclusion.

The results of this study dictate a need for insulin techniques awareness for the Lebanese population. The majority of our patients did not clean the site of injection before injecting insulin, did not rotate the site of administration, did not use a new needle for every injection, and did not throw away the needle directly after injections. However, those are the key factors for proper insulin administration in order to avoid infections. Patients should be instructed on the correct injection depth, injection sites, and injection technique. Insulin depth should be sufficient to avoid intramuscular injections that lead to rapid absorption and higher risk of hypoglycemia. ${ }^{23}$ For future reference, whenever needed, proper injection counseling for all insulin-naïve patients should provide an indispensable step in diabetes management and aid in reaching effective and safe diabetes control with the least possible injection complications. $^{24,25}$

\section{Conclusion}

In this study, more patients preferred the insulin pen over the conventional insulin device. The insulin pen was reported by patients to be easier to use and less painful. Hypoglycemic episodes and bruises at the site of administration were greater in patients using conventional insulin as compared to insulin pen users; however, a large sample size is needed and other factors should be investigated in order to have a significant relation. Patients in both groups need more awareness about the method of administration, aseptic injection techniques, and proper disposal of needles/syringes. Further research is desired to determine whether there is a difference between the insulin pen devices in terms of efficacy and acceptability. In fact, pharmacists can contribute to the safe use of insulin by offering patient counseling in the community setting prior to dispensing insulin. This might minimize errors related to administration, storage, and proper disposal of needles/syringes.

\section{Acknowledgment}

The authors gratefully acknowledge the assistance of Dr Hamzeh H Ramadan, PhD, in applying the statistical tests and reviewing the statistical analysis.

\section{Disclosure}

The authors report no conflicts of interest in this work.

\section{References}

1. de Bode C. 10 facts about diabetes [webpage on the Internet]. Geneva: World Health Organization; 2014. Available from: http://www.who. int/features/factfiles/diabetes/facts/en/. Accessed July 1, 2014.

2. Brunton S. Insulin delivery systems: reducing barriers to insulin therapy and advancing diabetes mellitus treatment. Am J Med. 2008; 121(6 Suppl):S35-S41.

3. Wright B, Bellone J, McCoy E. A review of insulin pen devices and use in the elderly diabetic population. Clinical Medicine Insights: Endocrinology and Diabetes. 2010;3:53-63.

4. American Diabetes Association. Standards of medical care in diabetes 2014. Diabetes Care. 2014;37 Suppl 1:S14-S80.

5. Meece J. Effect of insulin pen devices on the management of diabetes mellitus. Am J Health Syst Pharm. 2008;65(11):1076-1082.

6. [No authors listed]. United Kingdom Prospective Diabetes Study (UKPDS). 13: Relative efficacy of randomly allocated diet, sulphonylurea, insulin, or metformin in patients with newly diagnosed non-insulin dependent diabetes followed for three years. BMJ. 1995;310(6972): $83-88$.

7. Peyrot M, Rubin RR, Lauritzen T, et al; International DAWN Advisory Panel. Resistance to insulin therapy among patients and providers: results of the cross-national Diabetes Attitudes, Wishes, and Needs (DAWN) study. Diabetes Care. 2005;28(11):2673-2679.

8. Koro CE, Bowlin SJ, Bourgeois N, Fedder DO. Glycemic control from 1988 to 2000 among U.S. adults diagnosed with type 2 diabetes: a preliminary report. Diabetes Care. 2004;27(1):17-20.

9. Korytkowski M, Bell D, Jacobsen C, Suwannasari R; FlexPen Study Team. A multicenter, randomized, open-label, comparative, two-period crossover trial of preference, efficacy, and safety profiles of a prefilled, disposable pen and conventional vial/syringe for insulin injection in patients with type 1 or 2 diabetes mellitus. Clin Ther. 2003;25(11): 2836-2848.

10. Egekvist H, Bjerring P, Arendt-Nielsen L. Pain and mechanical injury of human skin following needle insertions. Eur J Pain. 1999;3(1):41-49.

11. NovoLet ${ }^{\circledR}$. Novo Nordisk India. Available from: www.novonordisk. co.in. Accessed July 1, 2014.

12. Bailey TS, Edelman SV. Insulin pen use for type 2 diabetes - a clinical perspective. Diabetes Technol Ther. 2010;12 Suppl 1:S86-S90.

13. Pawaskar MD, Camacho FT, Anderson RT, Cobden D, Joshi AV, Balkrishnan R. Health care costs and medication adherence associated with initiation of insulin pen therapy in Medicaid-enrolled patients with type 2 diabetes: a retrospective database analysis. Clin Ther. 2007;29(6Pt1): 1294-1305.

14. Asamoah E. Insulin pen-the "iPod" for insulin delivery (why pen wins over syringe). J Diabetes Sci Technol. 2008;2(2):292-296.

15. Lee WC, Balu S, Cobden D, Joshi AV, Pashos CL. Medication adherence and the associated health-economic impact among patients with type 2 diabetes mellitus converting to insulin pen therapy: an analysis of third-party managed care claims data. Clin Ther. 2006;28(10): $1712-1725$.

16. Hansen B, Lilleøre SK, Ter-Borch G. Needle with a novel attachment versus conventional screw-thread needles: a preference and usability test among adults with diabetes and impaired manual dexterity. Diabetes Technol Ther. 2011;13(5):579-585. 
17. Coscelli C, Lostia S, Lunetta M, Nosari I, Coronel GA. Safety, efficacy, acceptability of a pre-filled insulin pen in diabetic patients over 60 years old. Diabetes Res Clin Pract. 1995;28(3):173-177.

18. Lee IT, Liu HC, Liau YJ, Lee WJ, Huang CN, Sheu WH. Improvement in health-related quality of life, independent of fasting glucose concentration, via insulin pen device in diabetic patients. J Eval Clin Pract. 2009;15(4):699-703.

19. Wood L, Wilbourne J, Kyne-Grzebalski D. Administration of insulin by injection. Practical Diabetes International. 2002;19(2-1):S1-S4.

20. Miyakoshi M, Kamoi K, Iwanaga M, Hoshiyama A, Yamada A. Comparison of patient's preference, pain perception, and usability between Micro Fine Plus 31-gauge needle and Microtapered NanoPass 33-gauge needle for insulin therapy. J Diabetes Sci Technol. 2007;1(5):718-724.
21. Kesson CM, Bailie GR. Do diabetic patients inject accurate doses of insulin? Diabetes Care. 1981;4:333.

22. Luijf YM, DeVries JH. Dosing accuracy of insulin pens versus conventional syringes and vials. Diabetes Technol Ther. 2010;12 Suppl 1: S73-S77.

23. Thow $\mathrm{J}$, Home P. Insulin injection technique: depth of injection is important. BMJ. 1990;301(6742):3-4.

24. King L. Subcutaneous insulin injection technique. Nursing Standard. 2003;7(34): 45-52.

25. Frid A, Hirsch L, Gaspar R, et al; Scientific Advisory Board for the Third Injection Technique Workshop. New injection recommendations for patients with diabetes. Diabetes Metab. 2010;36 Suppl 2: S3-S18. 


\section{Supplementary materials}

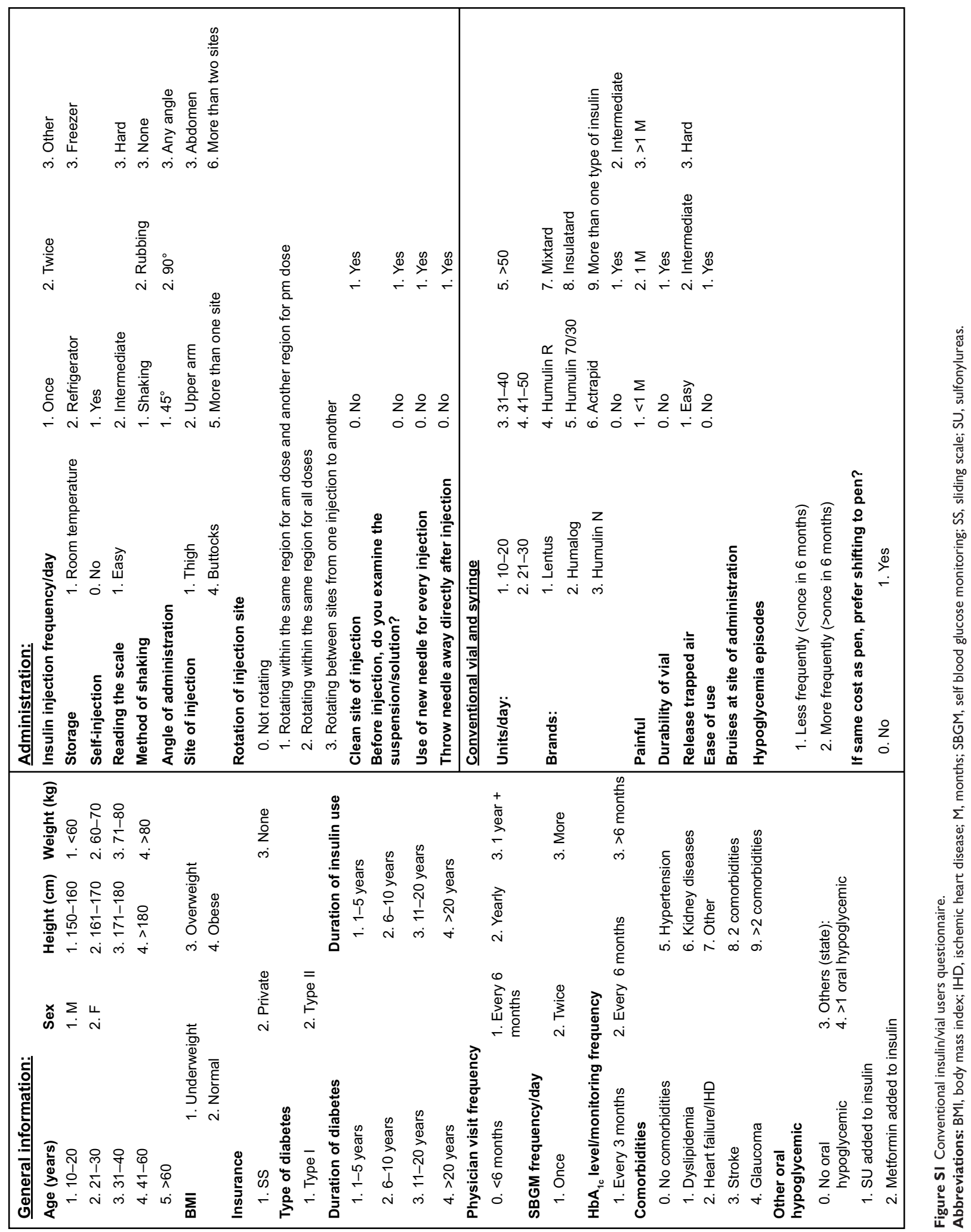




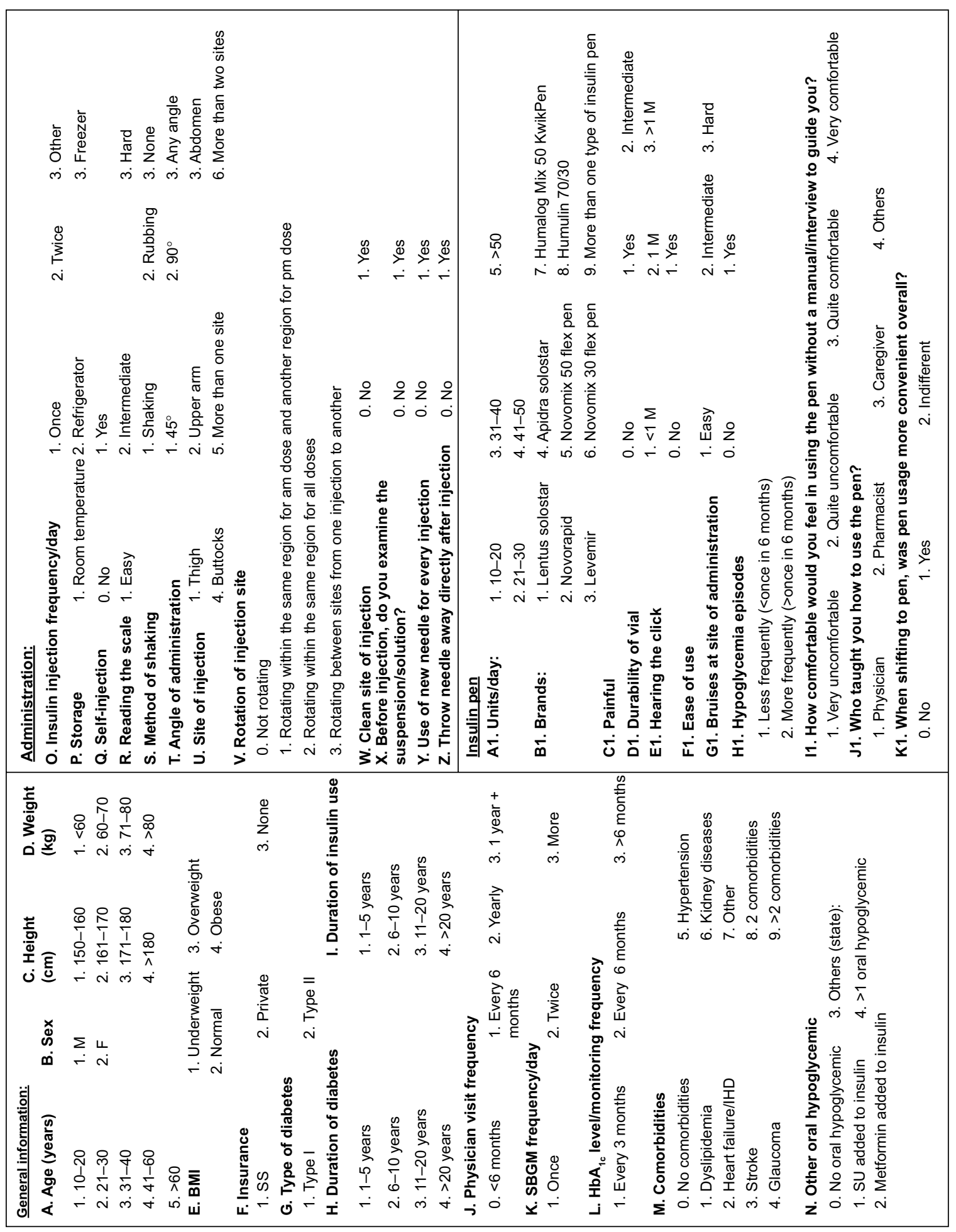

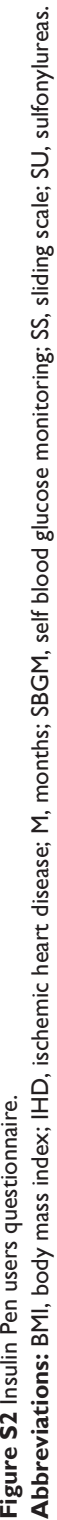




\section{Publish your work in this journal}

Patient Preference and Adherence is an international, peer-reviewed, open access journal that focuses on the growing importance of patient preference and adherence throughout the therapeutic continuum. Patient satisfaction, acceptability, quality of life, compliance, persistence and their role in developing new therapeutic modalities and compounds to optimize

clinical outcomes for existing disease states are major areas of interest for the journal. This journal has been accepted for indexing on PubMed Central. The manuscript management system is completely online and includes a very quick and fair peer-review system, which is all easy to use. Visit http://www. dovepress.com/testimonials.php to read real quotes from published authors.

Submit your manuscript here: http://www.dovepress.com/patient-preference-and-adherence-journal 